\title{
FACTORES DE RIESGO PREDICTORES DE LA NECESIDAD DEL USO DE INSULINA EN PACIENTES CON DIABETES GESTACIONAL
}

\section{PREDICTIVE RISK FACTORS OF INSULIN USE REQUIREMENT IN PATIENTS WITH GESTATIONAL DIABETES}

Cecilia Bufaliza, María Laura Cuello, Silvina A Siracusa, Agostina Mariotti, Jorge G López, Carlos Cuello

Hospital Del Carmen OSEP, Mendoza, Argentina

Introducción: la diabetes gestacional (DMG) es la alteración de la tolerancia a la glucosa que comienza o es reconocida por primera vez durante el embarazo en curso.

Un mal control glucémico aumenta el riesgo de complicaciones materno-fetales severas, por lo cual el manejo estricto de la DMG es primordial para prevenirlas.

La elección del tratamiento con plan nutricional o insulina depende fundamentalmente de los objetivos glucémicos alcanzados, y reconocer los factores de riesgo predictores de su fracaso permite optimizar este manejo.

Objetivos: determinar los factores de riesgo predictores de la necesidad del uso de insulina en DMG.

Materiales y métodos: estudio analítico, observacional, retrospectivo y de corte transversal en 107 pacientes con diagnóstico de DMG, durante los meses de marzo a diciembre de 2016. El estudio de los datos se realizó mediante análisis de pruebas de $X^{2} \mathrm{y}$ los resultados presentados en porcentajes $y$ valores de odds ratio.

Resultados: se analizaron 107 casos de mujeres con diagnóstico de DMG, de las cuales $56(52,34 \%)$ recibieron sólo tratamiento con plan nutricional, mientras que las restantes 51 (47,66\%) iniciaron insulinoterapia. Los factores de riesgo más relevantes asociados a la necesidad del uso de insulina fueron glu- cemias en ayunas mayores a $85 \mathrm{mg} / \mathrm{dl}$ en el primer trimestre (OR 3.93), sobrepeso u obesidad pregestacional (OR 3.2), diagnóstico de DMG antes de la semana 20 (OR 3.2), antecedentes personales de DMG (OR 2.5) o de macrosomía (OR 2.1), edad materna mayor a 30 años (OR 1.8), multiparidad (OR 1.7) y antecedentes de familiares de primer grado con DM (OR 1.2).

Conclusiones: la DMG es un importante desorden metabólico que trae aparejados pobres resultados tanto maternos como fetales. La insulina es la única droga aprobada para su manejo, por lo cual resulta importante determinar los factores predictores de la necesidad prenatal del uso de la misma.

En nuestro estudio demostramos que la glucemia elevada en el primer trimestre, el sobrepeso o la obesidad pregestacional y el diagnóstico de DMG antes de las 20 semanas implican un riesgo tres veces mayor respecto del grupo control. Reconocer estos factores predictores advierte de un eventual fracaso de las metas glucémicas tras el plan nutricional y obliga a un seguimiento más estricto y un temprano inicio de insulinoterapia.

Palabras clave: diabetes gestacional, insulina, factores de riesgo.

Key words: gestational diabetes, insulin, risk factors. 